\title{
Review article: prenatal diagnosis and management of sacrococcygeal teratoma, a review of literature
}

\section{Introduction}

A tumor formed from different tissues derived from the 3 germ cell layers away from anatomic place in which it develops. With advancement in ultrasound, more sacrococcygeal teratomas (SCT) are now diagnosed prenatally. ${ }^{1}$

It usually develops near coccyx, where the greatest amount of primitive cells is present for a long time.

Prevalence: Most common tumor of the newborn, with a prevalence of 0.25-0.28:10,000 live births.

Etiology: Arises from pleuripotent cells of Hensen"s node that is present anterior to coccyx.

Pathogenesis: pleuripotent cell line escapes from control of embryonic inducers and organizers and differentiates into tissues that is not usually present in the sacrococcygeal area. The teratomas develop and mature during intrauterine life, and get a growth that mnatches fetal growth. ${ }^{2}$

Associated anomalies: There is no specific abnormality that is more commonly present in sacrococcygeal teratomas than others. Documented anomalies involve gastrointestinal tract, musculoskeletal, CNS, renal and cardiac abnormalities. ${ }^{3,4}$

Differential diagnosis: Meningomyelocele, intracanalicular epidermoid tumors, lipomas dermal sinus stalks, hydromyelia, extrarenal Wilms" tumors, retrorectal hamartomas, neuroblastoas, and pacinomas. ${ }^{5}$

Prognosis: Most sacrococcygeal tumors are benign, morbidity and mortality are documented in some cases due to prematurity of the infant, traumatic delivery, dystocia and, bleeding in the tumor, or high output heart failure secondary to a steal phenomenon. Prognosis good after a successful excision of benign sacrococcygeal teratomas. ${ }^{2}$

Risk of Recurrence: sporadically, although a familial predisposition of presacral teratomas is reported. ${ }^{2}$

Management: Management depends on fetal lung maturation and presence of placental enlargement and/or fetal hydrops. When maturity of fetal lung without placental enlargement and/or hydrops fetalis, planned cesarean section is indicated. Placentomegaly and/ or hydrops develops it denotes a preterminal event and vecessitates emergency cesarean section or possible fetal surgical intervention. ${ }^{4}$

Our team in National research centre fetal unit, Cairo fetal medicine unit diagnosed 23 cases of sacrococcygeal teratoma in the period from January 2015 till January 2017, and a review of these cases regarding their prenatal diagnosis, management was made by the team.

All ladies were delivered by classical cesarean section at 38 weeks of gestation and a multidisciplinary team was always consulted with pediatric consultant, pediatric surgeons with immediate postnatal surgical excision of the mass.

Among these 23 cases, 3 of them only developed fetal ascites
Volume 10 Issue I - 2019

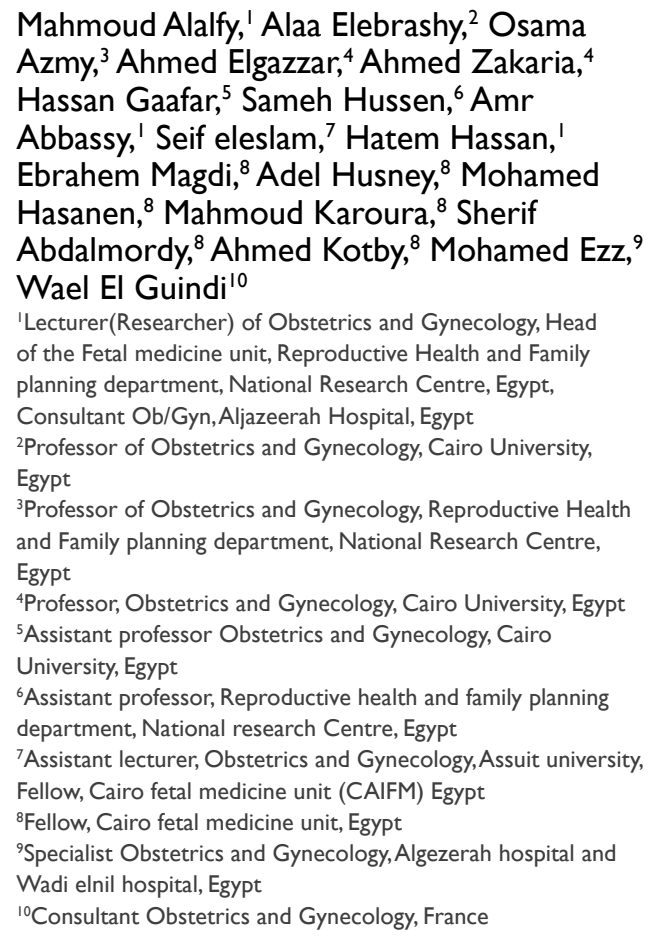

Mahmoud Alalfy,' Alaa Elebrashy, ${ }^{2}$ Osama Azmy, ${ }^{3}$ Ahmed Elgazzar, ${ }^{4}$ Ahmed Zakaria, ${ }^{4}$ Hassan Gaafar, ${ }^{5}$ Sameh Hussen, ${ }^{6}$ Amr Abbassy,' Seif eleslam, ${ }^{7}$ Hatem Hassan,' Ebrahem Magdi, ${ }^{8}$ Adel Husney, ${ }^{8}$ Mohamed Hasanen, ${ }^{8}$ Mahmoud Karoura, ${ }^{8}$ Sherif Abdalmordy, ${ }^{8}$ Ahmed Kotby, ${ }^{8}$ Mohamed Ezz, ${ }^{9}$ Wael El Guindi ${ }^{10}$

'Lecturer(Researcher) of Obstetrics and Gynecology, Head of the Fetal medicine unit, Reproductive Health and Family planning department, National Research Centre, Egypt, Consultant Ob/Gyn, Aljazeerah Hospital, Egypt 2Professor of Obstetrics and Gynecology, Cairo University, Egypt

${ }^{3}$ Professor of Obstetrics and Gynecology, Reproductive Health and Family planning department, National Research Centre, Egypt ${ }^{4}$ Professor, Obstetrics and Gynecology, Cairo University, Egypt ${ }^{5}$ Assistant professor Obstetrics and Gynecology, Cairo University, Egypt

${ }^{6}$ Assistant professor, Reproductive health and family planning department, National research Centre, Egypt

${ }^{7}$ Assistant lecturer, Obstetrics and Gynecology, Assuit university, Fellow, Cairo fetal medicine unit (CAIFM) Egypt

${ }^{8}$ Fellow, Cairo fetal medicine unit, Egypt

'Specialist Obstetrics and Gynecology,Algezerah hospital and Wadi elnil hospital, Egypt

${ }^{10} \mathrm{Consultant}$ Obstetrics and Gynecology, France

Correspondence: Mahmoud Alalfy, Lecturer(Researcher) of Obstetrics and Gynecology, Reproductive Health and Family planning department, National Research Centre, The senior Fellow, CAIFM, Consultant Ob/Gyn,Aljazeerah Hospital, Egypt, Tel +2 010026 I 1058, Email mahmoudalalfy@ymail.com

Received: January 15, 2019 | Published: February 07, 2019

and hydrops and one of them died postnatal while the other 2 fetuses improved postnatally after surgical excision of the mass.

The remaining 20 cases who did not develop hydrops, the had completely normal outcome postnatally after surgical intervention with excision of the teratomas.

The ultrasound criteria for diagnosis can revealed a large mass which is related to the fetal sacrum with high vascularity as demonstrated in (Figure 1).

Moreover 3D rendering image can show the large mass which is related to the lower back of the fetus as shown in (Figure 2).

\section{Prenatal diagnosis}

A mass related to the fetal rump is mostly a teratoma after ruling out a meningomyelocele. ${ }^{6}$ A sacrococcygeal teratoma could be differentiated from meningomyelocele by presence of internal soft tissue while meningocele is cystic in content. ${ }^{7}$ alpha-Fetoprotein may be normal or increased in sacrococcygeal teratomas and ultrasound differentiate sacrococcygeal teratoma from meningocele. ${ }^{8}$ 


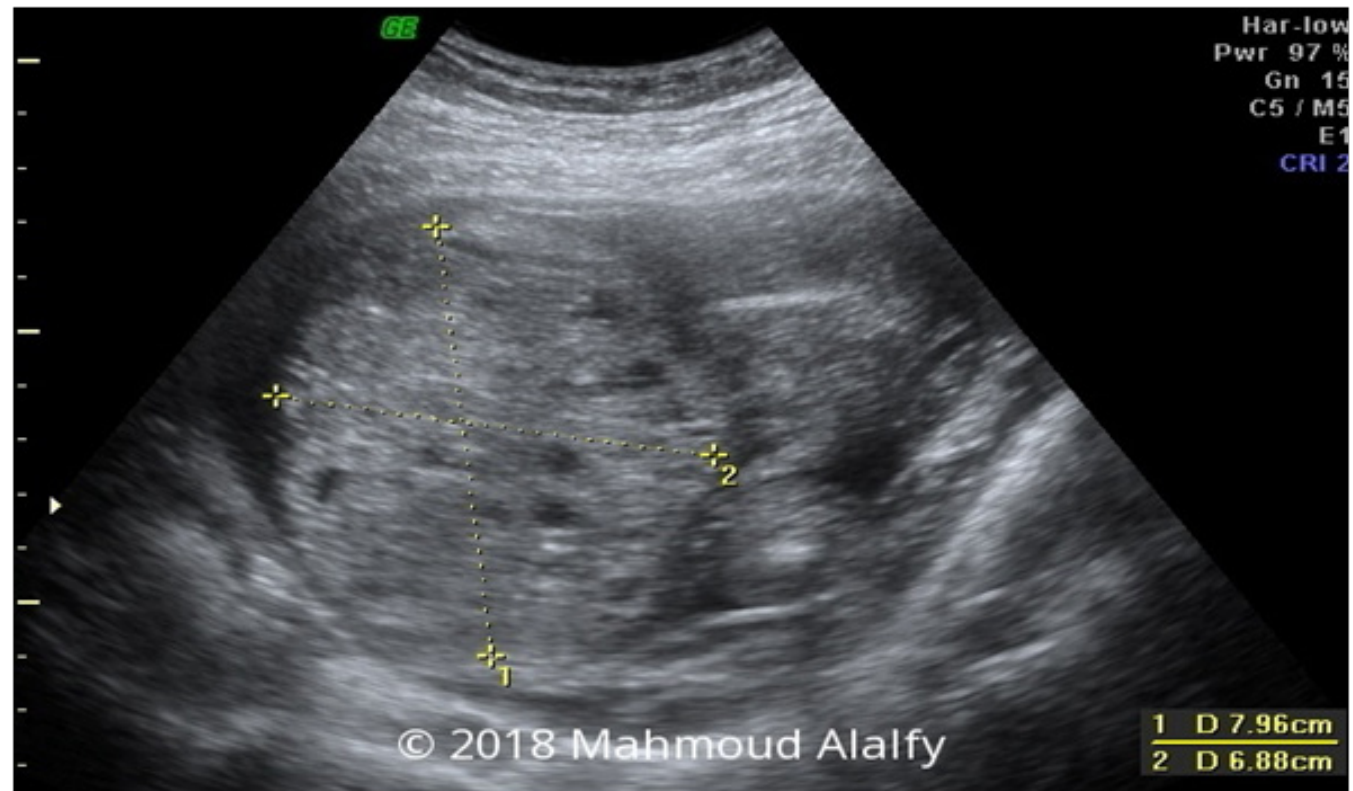

Figure I 2 D image demonstrates a mass related to the fetal sacrum and coccyx.

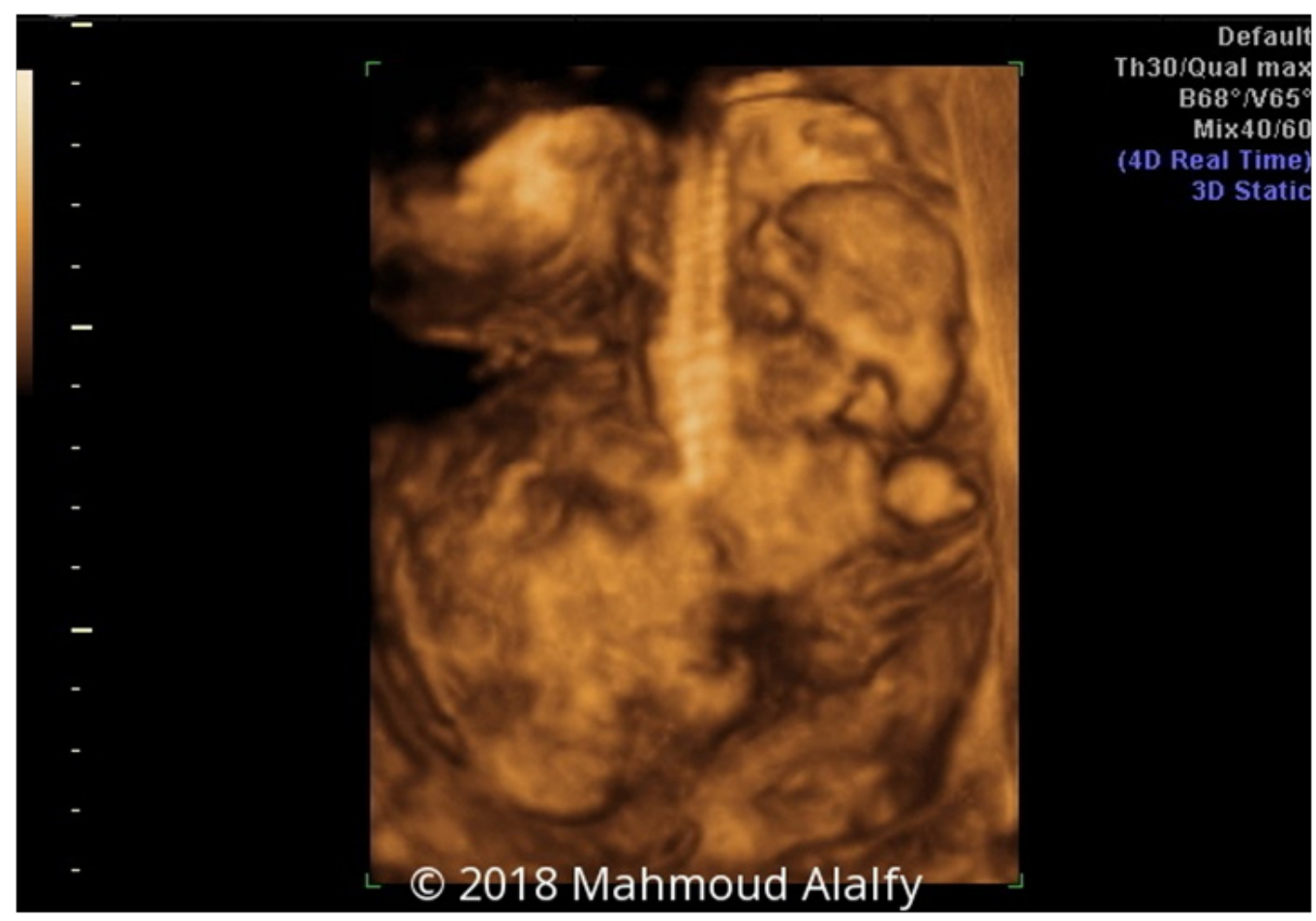

Figure 2 3D render image demonstrates the sacrococcygeal teratoma.

\section{Management}

Most fetal teratomas could be managed by planned delivery and postnatal surgery. Holzgreve et al. ${ }^{5}$ have described an algorithm to approach the management of SCT based on maturity of lung and the presence or absence of placental enlargement and hydrops. ${ }^{5}$ When placental enlargement or hydrops did not occur, the fetus has to be monitored by ultrasonography until fetal lung maturity is reached. The patient should then undergo elective early delivery by cesarean section to prevent trauma to the SCT or shoulder dystocia. ${ }^{5}$

The occurrence of placentomegaly and/or hydrops fetalis is thought to be an adverse effect that denotes imminent fetal loss. When it is present with evidence of lung maturation necessitates an emergency delivery. While if these adverse effect occurred before lung maturation are hard to manage with consideration of intrauterine blood transfusion. ${ }^{5}$

Prognosis of SCT becomes better nowadays due to antenatal diagnosis, planned delivery, and proper surgical excision. ${ }^{9}$

Sacrococcygeal tumor is the most common tumor diagnosed in fetus. SCT has been classified as four types based on weather tumor are external and/or internal. The spinal cord involvement of SCT is rare and management involves resection and close follow up..$^{10}$ 
Differential diagnosis that could be distinguished by MRI ultrasound and histopathology includes neuroblastoma, extraspinal ependymoma, ependymoblastoma, rhabdomyosarcoma and terminal myelocystocele. ${ }^{11,12}$

Treatments of sacrococcygeal teratoma that have spinal extension consist of excision of the tumor then follow up. ${ }^{13,14}$

\section{Conclusion}

Sacrococcygeal teratoma is a tumor with a fair prognosis when it is early and properly diagnosed prenatally and good intrapartum and postpartum management is planned and proper resection is made.

\section{Author contributions}

1. The team of authors participated in this study in its aspects with Substantial contributions to the conception or design of the work; or the acquisition, analysis, or interpretation of data for the work; AND

2. Drafting the work or revising it critically for important intellectual content;

3. Final approval of the version to be published; AND

4. Agreement to be accountable for all aspects of the work in ensuring that questions related to the accuracy or integrity of any part of the work are appropriately investigated and resolved.

In addition to the above mentioned participation of the authors, they performed the prenatal diagnosis, counseling; follow up of the cases and performing the delivery.

\section{Acknowledgment}

We would like to thank all members of the fetal medicine unit in National research Centre and Cairo fetal medicine

\section{Conflicts of interest}

The authors declare no conflicts of interest.

\section{References}

1. El-Quarmalawi MA, Saddik M, el Abdel Hadi F, et al. Diagnosis and management of fetal sacrococcygeal teratoma. Int J Gynecol Obstet. 1990;31(3):275-281.
2. Sheth S, Nussbau AR, Sanders R, et al. Prenatal diagnosis of sacrococcygeal teratoma: sonographic-pathologic correlation. Radiology. 1988;169(!):131-136.

3. Ein SH, Adeyemi D, Mancer K. Benign sacrococcygeal teratomas in infants and children: a 25 year review. Ann Surg. 1979;191(3):382-384.

4. Altman RP, Randolph JG, Lilly JR. Sacrococcygeal teratoma: American academy of pediatrics surgical section survey-1973. J Ped Surg. 1974;9(3):389-398.

5. Holzgreve W, Flake AW, Langer JC. The fetus with sacrococcygeal teratoma. In: Harrison M, Golbus M, Filly RA, editors. The unborn patient. Philadelphia: WB Saunders; 1991:460-469.

6. Kuhlmann RS, Warsof SL, Levy DL, et al. Fetal sacrococcygeal teratoma. Fetal Therapy. 1987;2:95-100.

7. Sherowsky RC, Williams $\mathrm{CH}$, Nichols VB, et al. Prenatal ultrasonographic diagnosis of a sacrococcygeal teratoma in twin pregnancy. J Ultrasound Med. 1985;4(3):159-161.

8. Holzgreve W, Miny P, Anderson R, et al. Experience with 8 cases of prenatally diagnosed sacrococcygeal teratomas. Fetal Therapy. 1987;2(2):88-94.

9. Hogge WA, Thiagarajah S, Barber VG, et al. Cystic sacrococcygeal teratomas:ultrasound diagnosis and perinatal management. $J$ Ultrasound Med. 1987;6(12):707-710.

10. Sharma D, Murki S, Pratap T. Sacrococcygeal teratoma - an interesting case and infrequently seen extension in spinal cord. J Neonatal Biol. 2017;6:255.

11. Yu JA, Sohaey R, Kennedy AM, et al. Terminal myelocystocele and sacrococcygeal teratoma: A comparison of fetal ultrasound presentation and perinatal risk. AJNR Am J Neuroradiol. 2007;28(6):1058-1060.

12. Santi M, Bulas D, Fasano R, et al. Congenital ependymoblastoma arising in the sacrococcygeal soft tissue: a case study. Clin Neuropathol. 2008;27(2):78-82.

13. Jelin E, Jelin AC, Lee H. Sacrococcygeal teratoma with spinal canal invasion prenatally diagnosed. J Pediatr Surg. 2009;44(4):E9-E11.

14. Shahjouei S, Hanaei S, Nejat F, et al. Sacrococcygeal teratoma with intradural extension: case report. J Neurosurg Pediatr. 2015;15(4):380383. 